\title{
Situs Inversus Totalis'li Olguda Torakal Epidural Anestezi ile Laparoskopik Kolesistektomi
}

\section{Laparoscopic Cholecystectomy Under Thoracic Epidural Anaesthesia in Patients with Situs Inversus Totalis}

\author{
Serkan Telli, Pınar Yavaşca, Ali Bestami Kepekçi, Elif Erdoğan \\ Haseki Eğitim ve Araştırma Hastanesi, 2. Anesteziyoloji ve Reanimasyon Kliniği, Istanbul, Türkiye
}

Özet

Genel anestezi ile birlikte torakal epidural anestezi uygulanarak başarılı batın operasyonları gerçekleştirildiği bilinmektedir. Sunumuzda, situs inversus totalisi olan ve laparoskopik kolesistektomi operasyonu geçirecek akut kolesistitli hastada uyguladığımız segmental torakal epidural anestezi vesilesiyle bu teknik literatür eşliğinde tartışılmıştır. (Haseki Tıp Bülteni 2014; 52: 53-5)

Anahtar Kelimeler: Torakal epidural anestezi, laparoskopik kolesistektomi, cerrahi stress cevabı

\section{Giriş}

Intraoperatif cerrahi stres, plazma katekolamin konsantrasyonunu ve adrenerjik aktiviteyi önemli derecede arttırır ve bunun sonucunda periferik vazokonstriksiyon, azalan oksijen parsiyel basıncı sebebiyle doku hipoksisi ortaya çıkar. Bu da, operasyon sonrası doku iyileşmesinde azalma ve enfeksiyonda artma ile sonuçlanır. Torakal epidural anestezi (TEA) ağrılı uyaran varlığında afferent sinir bloğu yaparken efferent sempatik deşarjı da inhibe eder. Bunun sonucunda da oksijenizasyon artar ve doku iyileşmesi hızlandığı gibi enfeksiyon riski de azalır (1).

Bizim vakamı; daha önce batın operasyonu geçirmiş olan ve nadir görülen situs inversus totalisli bir hastaydı ve hastamız mümkünse genel anestezi almak istemediğini beyan etti. Bu nedenle hastanın da onamı alınarak segmental TEA uygulanarak operasyon gerçekleştirildi.
Abstract

Segmental epidural anesthesia induced by administering low doses of local anesthetics into mid-thoracic segments is successfully implemented in upper abdominal operations, such as cholecystectomy. In this paper, we present a patient with situs inversus who underwent laparoscopic cholecystecto my for acute cholecystitis under thoracic segmental epidural anesthesia and, we discuss this anesthetic technique in the light of the literature. (The Medical Bulletin of Haseki 2014; 52: 53-5)

Key Words: Thoracic epidural anaesthesia, laparoscopic cholecystectomy, surgical stress response

\section{Olgu}

Kırk dokuz yaşında, $155 \mathrm{~cm}$ boyunda, 68 kg ağırlığında taşlı kolesistit tanısıyla cerrahi planlanan kadın hastanın öyküsünde situs inversus ve geçirilmiş akut romatizmal ateş mevcuttu. Kronik steroid kullanımı olan hastaya steroid şemsiyesi uygulanmasına karar verilerek preoperatif dönemde 20 mg kortikosteroid intravenöz olarak uygulandı ve cerrahi tedavi için segmental torakal epidural anesteziye karar verildi. Premedikasyon verilmeden operasyon odasına alınan hastaya rutin monitorizasyonu takiben periferik damar yolu açılarak $500 \mathrm{ml} \% 0.9^{\prime}$ luk NaCl ile ön yükleme yapıldı. İşlem öncesi hastadan arter kan gazı alındı. Daha sonra oturur pozisyona alınan hastada, $18 \mathrm{G}$ Touhy iğnesi ile $T_{9-10}$ aralığından asılı damla yöntemiyle epidural aralığa ulaşıldı. $3 \mathrm{ml} \% 2^{\prime}$ lik prilokain test dozu uygulandı. Epidural aralıkta olduğumuz teyit edildikten 
sonra kateterizasyon uygulandı. Kateter ucu $4 \mathrm{~cm}$ sefale doğru ilerletildi ve takiben $7 \mathrm{ml} \% 0.5^{\prime}$ lik bupivakain ve 50 $\mu \mathrm{g}$ fentanyl karışımı verildi. Test dozundan itibaren $10 \mathrm{dk}$ geçtikten sonra yapılan pinprick testinde $T_{5}-T_{12}$ segmentleri arasında yeterli sensoryal blok elde edildi. Hastada yapılan motor muayenede bromage bir idi. Hastaya $1.5 \mathrm{mg}$ midazolam intravenöz uygulandı. Cerrahinin başlaması için gerekli intraabdominal basınç 8-10 mmHg değerine 1 $\mathrm{ml} / \mathrm{dk}$ hızında ulaşıldıktan sonra operasyon başlatıldı. Batın içi basıncın en fazla 12 mmHg'ya kadar çıkmasına izin verildi. Operasyon süresince yüz maskesiyle $4 \mathrm{~L} / \mathrm{dk}$ akımla $\mathrm{O}_{2}$ uygulanan hastada karın içi $\mathrm{CO}_{2}$ basıncı $8-9 \mathrm{mmHg}$ olarak ayarlandı. Intraoperatif olarak kalp hızı 68-96 atım/ dk, noninvazif kan basıncı 133/83-102/64 mmHg ve $\mathrm{SpO}_{2} \% 97-\% 100$ aralığında seyretti. Epidural anesteziden yaklaşık 35 dakika sonra hastanın kalp hızı 47 atım/dk'ya düştü ve $0.5 \mathrm{mg}$ atropin uygulaması ile kısa sürede normale döndü. Operasyonun 20. dk'sında hastamız çok şiddetli olmayan omuz ağrısı tariff etti. VAS (visual analog skor) dört olarak değerlendirildi ve ameliyatın 40. dakikasında Ramsey skoru iki olacak şekilde sedasyon sağlamak amaçlı propofol infüzyonu başlandı. Perop 50. dakikada alınan arteriyal kan gazı değerinde $\mathrm{pH}=7,28 \mathrm{pCO}_{2}=50 \mathrm{mmHg}$ olması üzerine hastaya derin ve sık nefes alıp vermesi telkin edildi (Tablo 1). Operasyonun birinci saatinde epidural kateterden ek doz olarak $3 \mathrm{ml} \% 0.5^{\prime}$ lik bupivakain uygulandı. Operasyon $120 \mathrm{dk}$. sonunda komplikasyonsuz olarak tamamlandı. Hastada intraoperatif ve postoperatif solunum sıkıntısı gözlemlenmedi. Hastanın batınından gaz boşaltıldıktan sonra tekrar alınan arter kan gazında asidozun düzeldiği ve $\mathrm{PCO}_{2}{ }^{\prime}$ nin de 40 mmHg'ya düştüğü görüldü (Tablo 1). Cerrahiden yaklaşık 3 saat sonra VAS skoru altı olarak değerlendirildi ve tedavisi için epidural kateterden $3 \mathrm{ml} \% 0.5^{\prime}$ lik bupivakain ve $50 \mu \mathrm{g}$ fentanil uygulandı. 30. dakika, 3. saat ve 12 . saatlerde ağrı takibi yapılan hastanın postop ek doz analjezi ihtiyacı olmadı. Ertesi gün kateter çıkarıldı. Hasta postoperatif birinci gün vital bulguları stabil olarak taburcu edildi.

\begin{tabular}{|l|c|c|c|}
\hline $\begin{array}{l}\text { Tablo 1. Hastanın Arteriyel Kan Gazı değerleri (preoperative } \\
\text { 4L/dk } \mathrm{O}_{2} \text { uygulandı) }\end{array}$ & Pre-op & Per-op & Post-op \\
\hline & 7.377 & 7.28 & 7.34 \\
\hline $\mathbf{P h}$ & 190 & 131 & 88.9 \\
\hline $\mathbf{P O}_{\mathbf{2}}$ ( $\left.\mathbf{m m H g}\right)$ & 39.2 & 50.6 & 42.6 \\
\hline $\mathbf{P C O}_{\mathbf{2}}$ (mmHg) & 22.5 & 23.6 & 22.8 \\
\hline $\mathbf{H C O}_{\mathbf{3}}$ (mmol/L) & -2.0 & -3.6 & -2.6 \\
\hline $\mathbf{B E}(\mathbf{m m o l} / \mathbf{L})$ & 99 & 98 & 98 \\
\hline $\mathbf{S p O}_{\mathbf{2}} \mathbf{( \% )}$ & & &
\end{tabular}

\section{Tartışma}

Konvansiyonel üst abdominal girişimlerin solunum mekaniklerinde bozulma ve pulmoner komplikasyonlarda artışa yol açması nedeniyle cerrahi işlemin laparoskopik olarak uygulanması gerektiği savunulmaktadır $(2,3)$. TEA, laparoskopik kolesistektomide primer anestezik teknik olarak nadiren kullanılsa da solunum problemi olmayan hastalarda iyi tolere edildiği ve yeterli analjezi sağladığı gösterilmiştir (4). Epidural anestezi ise hızlı ve sorunsuz bir postoperatif iyileşme sağlar. Genel anestezinin avantajı ise kontrollü mekanik ventilasyonla $\mathrm{CO}_{2}$ pnömoperitonyumun neden olduğu solunumsal asidozun kompanse edilebilmesidir. Ancak yüz maskesiyle yeterli oksijen uygulanan TEA'li hastalarda da bu durumun azaltılabileceği gösterilmiştir (5). Bu yüzden hastamıza operasyon süresince yüz maskesi ile oksijen uyguladık. Operasyonun planlanandan daha uzun sürdüğü görülünce 50 . dakikada aldığımız kan gazında respiratuar asidoz gelişti. Özellikle bilinci açık ve koopere olabilen hastanın daha sık nefes alıp vermesi sağlandıktan sonar, bu asidoz hızlıca düzelebildi. Kim YI ve ark., solunum fonksiyon testleri ciddi derecede bozuk ileri yaştaki bir hastada TEA ile uyguladıkları laparoskopik kolesistektomi deneyimlerini bildirmişlerdir. $\mathrm{Bu}$ hastada yüksek hızda yanlışlıkla uygulanan $\mathrm{CO}_{2}$ insüflasyonuna bağlı gelişen pnömoperitonyumun neden olduğu ani bradikardi, hipotansiyon ile beraberinde görülen abdomen ve omuz ağrısı nedeniyle, $\mathrm{CO}_{2}$ insüflasyonunun 1 L/dk hızla yapılmasının önemini vurgulamışlardır (6). Hastamıza uygulanan $\mathrm{CO}_{2}$ insüflasyon hızının $1 \mathrm{~L} / \mathrm{dk}$ ve en yüksek abdominal basıncın $12 \mathrm{mmHg}$ olması nedeniyle intraoperatif gelişen ve atropin uygulanması ile normale dönen bradikardinin sempatik bloğa bağlı olduğunu düşünülmüştür. Kronik obstrüktif akciğer hastalığı olan 6 ve 29 hastadan oluşan iki ayrı laporoskopik kolesistektomi serisinde, hastaların TEA altında başarıyla opere edildikleri bildirilmiştir $(6,7)$. Karabeyoğlu ve arkadaşları ciddi akciğer problemi olan akut kolesistitli bir hastada TEA yaklaşımlarını paylaştıkları yayında deneyimli ellerde, kısa operasyon süreleri ve düşük $\mathrm{CO}_{2}$ basınçlarında, TEA altında laparoskopik kolesistektominin ciddi solunum problemi olan hastalarda güvenle uygulanabileceği sonucuna vardıklarını belirterek herhangi bir komplikasyonla karşılaşmadıklarını ifade etmişlerdir (8). Subdiyafragmatik peritonun irritasyonu ya da mezenter traksiyonuna bağlı hastaların bir kısmında değişen derecelerde görülen omuz ağrısı intravenöz alfentanil uygulanmasıyla giderilebilmiştir (5). Bizim olgumuzda ise bu şikayet daha az olmuş intravenöz propofol infüzyonu uygulanarak ortadan 
kaldırılmıştır. Kapral ve ark.'nın çalışması göstermiştir ki, TEA'nin büyük abdominal cerrahi sırasında intramukozal pH'nın düşmesinde koruyucu etkisi vardır ki bu cerrahi stresin tedavisi için belki de en değerli araçtır (1). Pursnani'nin çalışması göstermiştir ki; majör abdominal cerrahi sırasında intramukozal pH'nın azalmasına torakal epidural anestezinin koruyucu etkisi vardır ve belki de cerrahi stresin tedavisi için elimizdeki en değerli araç torasik epidural anestezidir (9).

Her vaka, genel ve epidural anestezinin rölatif riskleri ve en iyi sonucun alınması açısından bağımsız olarak değerlendirilmelidir. Başta kronik obstrüktif akciğer hastalıklı hastalarda olmak üzere laporoskopik kolesistektomi TEA ile rahatlıkla uygulanabilir.

Operasyonun uzun sürmesi halinde hastalarda respiratuar asidoz derinleşebilir. Bu yüzden de başlangıçta uzun süreceği düşünülen operasyonlarda epidural anestezi tercih edilmemelidir (1). Solunum sıkıntısı nedeniyle genel anestezi uygulanması riskli olan hastalarda, deneyimli ellerde, kısa operasyon süreleri ve düşük $\mathrm{CO}_{2}$ basınçları uygulamak koşulu ile postop analjezi, erken hasta mobilizasyonu, iyileşmenin hızlanması ve erken taburcu amacıyla TEA altında laparoskopik kolesistektomi güvenle uygulanabileceği düşüncesindeyiz. Ama unutulmamalıdır ki, özellikle uzayan vakalarda gelişecek derin respiratuar asidoza karşı uyanık olmalı; gerekirse hastanın entübe edilip kontrole moda ventile edilmek zorunda kalınabileceği bilinilmelidir.

\section{Kaynaklar}

1. Kapral S, Gollmann G, Bachmann D, et al The Effects of Thoracic Epidural Anesthesia on Intraoperative Visceral Perfusion and Metabolism. Anesth Analg 1999;88:402-6.

2. Becqeumin JP, Piquet J, Becqeumin $M H$, Melliere $D$, Harf $A$. Pulmonary function after transverse or midline incision in patients with obstructive pulmonary disease. Intensive Care Med 1985;11:247-51.

3. Rademaker BM, Ringers J, Odoom JA, de Wit LT, Kalkman CJ, Oosting J. Pulmonary function and stress response after laparoscopic cholecystectomy: Comparison with subcostal incision and influence of thoracic epidural analgesia. Anesth Analg 1992; 75:381-5

4. Langenberg CJM, Huygan F, Go PMNYH, Gouma DJ. Thoracic epidural anaesthesia for laparoscopic cholecystectomy. Regional Anaesth 1992;17:35-9.

5. Ciofolo MJ, Clerque F, Seebacher J, Lefebre G, Viars P. Ventilatory effects of laparoscopy under epidural anesthesia. Anesth Analg 1990;70:357-61.

6. Kim YI, Lee JS, Jin HC, Chae WS, Kim SH. Thoracic epidural anesthesia for laparoscopic cholecystectomy in an elderly patient with severely impaired pulmonary function tests. Acta Anaesthesiol Scand 2007;51:1394-6.

7. Gramatica L, Brasesco OEJ, Mercado Luna A, Martinessi V, Panebianco G, et al. Laparoscopic cholecystectomy performed under regional anesthesia in patients with chronic obstructive pulmonary disease. Surg Endosc 2002;16:472-5.

8. Karabeyoğlu I, Muratlı N, Yoldaş S, ve ark. The thoracic segmental epidural anesthesia in a patient with severe lung disease; Dicle Tıp Derg / Dicle Med J Cilt / Vol 37, No 1, 54-6.

9. Pursnani KG, Bazza Y, Calleja M, Mughal MM. Laparoscopic cholecystectomy under epidural anesthesia in patients with chronic respiratory disease. Surg Endosc 1998;12:1082-4. 